\title{
An acute experimental study to evaluate the effect of gatifloxacin on blood sugar levels in diabetic and non-diabetic rabbits
}

\author{
Akash Ashok Khobragade ${ }^{1 *}$, Mrityunjay Prashant Khopkar ${ }^{1}$, Sadiq Bapumiya Patel ${ }^{1}$, \\ Snehal Prabhu Kosale ${ }^{2}$, Kamagonda Jalikar ${ }^{1}$
}

\begin{abstract}
${ }^{1}$ Department of Pharmacology, ${ }^{2}$ Department of Pathology, Grant Govt. Medical College, Mumbai, India
\end{abstract}

Received: 25 May 2016 Accepted: 01 July 2016

*Correspondence to: Dr. Akash Ashok Khobragade, Email: akash.khobragade@ gmail.com

Copyright: () the author(s), publisher and licensee Medip Academy. This is an openaccess article distributed under the terms of the Creative Commons Attribution NonCommercial License, which permits unrestricted noncommercial use, distribution, and reproduction in any medium, provided the original work is properly cited.

\begin{abstract}
Background: Diabetes mellitus is a condition characterized by chronic hyperglycemia and disturbance of carbohydrate, fat and protein metabolism associated with absolute or relative deficiencies in insulin secretion and/or insulin action. The objective of this study was to evaluate the effects of gatifloxacin on blood sugar levels in non-diabetic rabbits and alloxan induced diabetic rabbits.

Methods: Animals were fasted for 20 hours. Blood was collected for baseline investigations. After giving single oral dose of $2 \%$ gum acacia blood samples were drawn at 1,2 and 4 hours for estimation of glucose and serum insulin. After 2 days a repeat blood sample for baseline was collected after 20 hours fasting and single oral dose of gatifloxacin $25 \mathrm{mg} / \mathrm{kg}$ was given. Samples of blood were taken at 1, 2 and 4 hours. After a wash out period of 7 days injection alloxan $140 \mathrm{mg} / \mathrm{kg}$ was given slowly intravenously to induce diabetes in the animals. On day 3 after alloxan induction, blood samples were taken from the animals (fasting 20 hours), for baseline investigations. Same procedure of blood collection and timing was followed as done before diabetes induction. The animals were given a single dose of gatifloxacin $25 \mathrm{mg} / \mathrm{kg}$ with blood samples drawn at 1,2 and 4 hours for FBS and serum insulin.

Results: In non-diabetic rabbits, the effect of control and gatifloxacin on FBS levels at 1, 2 and 4 hours after administration was $100.3,101.35,102.89 \mathrm{mg} / \mathrm{dl}$ and $73.83,73.04,82.11 \mathrm{mg} / \mathrm{dl}$ respectively, on serum insulin levels at 2 hours interval was 3.62 and $4.16 \mu \mathrm{IU} / \mathrm{ml}$ respectively. 48 hours after alloxan induction FBS and insulin levels were 219.13 and $1.19 \mu \mathrm{IU} / \mathrm{ml}$. After alloxan induction, FBS levels at 1, 2, 4 hours for control and gatifloxacin are 221.01, 224.13, 228 and 218.60, 218.53, 220.01 respectively. At 2 hours interval serum insulin levels were 1.15 and $1.21 \mu \mathrm{IU} / \mathrm{ml}$ for control and gatifloxacin.

Conclusions: This study is in line with previous reports that gatifloxacin causes increased release of insulin leading to hypogycemia. The fall in blood sugar levels following a single oral dose of gatifloxacin is not limited to diabetic states alone and is more marked in non-diabetic rabbits.
\end{abstract}

Keywords: Diabetes Mellitus, Alloxan, Gatifloxacin, FBS, Insulin

\section{INTRODUCTION}

Diabetes mellitus is a condition characterized by chronic hyperglycemia and disturbance of carbohydrate, fat and protein metabolism associated with absolute or relative deficiencies in insulin secretion and /or insulin action. The cardinal symptoms are polyuria, polydipsia, and asthenia and weight loss. There is increased susceptibility to bacterial and fungal infections. ${ }^{1}$
Gatifloxacin, a fluroquinolone drug targets the bacterial DNA gyrase and topoisomerase IV. ${ }^{2}$ Anti-topoisomerase activity of fluoroquinolones is the main mechanism by which they inhibit gram positive organisms, while anti DNA gyrase activity is responsible for their action on gram negative ones. ${ }^{3}$

Several pre and post marketing studies (PMS) have unfaced a probable role of gatifloxacin in causing dysglycemia, i.e. both hypo and hyperglycemia, in 
elderly patients (reduced renal clearance). ${ }^{5}$ Two retrospective studies, conducted to evaluate the dysglycemic effects of gatifloxacin in patients for respiratory tract infections, also showed similar results. ${ }^{3,4}$ However these studies had several limitations that merit emphasis.

So this study was aimed to evaluate the effect of a single oral dose of gatifloxacin on fasting blood glucose and serum insulin level.

\section{METHODS}

All animals were procured from the animal house of department of pharmacology, Grant Government Medical College, Mumbai. Healthy male and female New Zealand albino rabbits weighing above $1.5 \mathrm{~kg}$ of age above 24 weeks were selected for this study. The study was conducted after approval from the institutional animal ethics committee. These animals were housed under standard laboratory conditions in a well-ventilated room and fed on standard pellet diet (Amrut laboratory animal feed, Nav Maharashtra Chakan Oil Mills Ltd. Crude protein $22.2 \%$, crude oil $4.2 \%$, crude fibre $7.1 \%$, Ash $7.2 \%$, sand silica $1.1 \%$ ). The animals had free access to diet and water and were placed in clean, neatly labelled cages containing two albino rabbits in each cage.

Drugs and chemicals used in this study was gatifloxacin (Dr. Reddy's Laboratories Ltd.). The human dose of tablet gatifloxacin is $400 \mathrm{mg} /$ day which were extrapolated to $19 \mathrm{mg} / \mathrm{kg} /$ day for rabbits. ${ }^{5,8}$ However, the levels might increase in case of reduced renal clearance. Therefore the drug was administered in a slightly higher dose i.e. $25 \mathrm{mg} / \mathrm{kg}$, as a single oral dose, for the study. ${ }^{9}$ Oral suspension of the drug was made in $2 \%$ gum acacia and dose was adjusted to a volume of 2-5 ml daily for albino rabbits, which was administered with the help of a feeding catheter. Study medication was administered to the fasting animals after drawing samples for baseline values.

\section{Experimental group}

\section{Normal control group}

8 rabbits were administered $2 \%$ gum acacia (single dose) as an oral suspension with a wash out period of 3 days. The same 8 rabbits were administered $25 \mathrm{mg} / \mathrm{kg}$ gatifloxacin (single dose) as an oral suspension in $2 \%$ gum acacia and were given a wash out period of 7 days.

\section{Diabetic group}

A diabetes like state was induced by Injection alloxan $140 \mathrm{mg} / \mathrm{kg}$ (made as $10 \%$ solution in distilled water) was given intravenously slowly in the marginal ear vein of the albino rabbits, to induce diabetes. Alloxan destroys the bcells of the pancreatic islets and diabetes like state is achieved in 12 hours of alloxan injection. After 48 hours, these 8 animals were administered $2 \%$ gum acacia as an oral suspension. They were given 3 days washing out period.

\section{Evaluation parameters}

\section{Collection of blood sample}

All the albino rabbits, found to be suitable for the study were fasted for 24 hours, placed in a rabbit holder and subsequently $5 \mathrm{ml}$ of blood was collected through the marginal ear vein after cleaning with xylene. The blood was placed in a neatly labelled fluoride and plain test tube. The blood samples were kept at room temperature for 2 hours for coagulation to be completed. Subsequently, the two sets of tubes were subjected to centrifugation and the supernatant plasma serum was separated.

\section{Biochemical parameters}

Fasting blood sugar was estimated within 24 hours of collection in $\mathrm{mg} / \mathrm{dl}$ by GOD/POD (glucose oxidase/ peroxidase) methods. ${ }^{10}$ Insulin estimation was done using 125 I RIA kit. ${ }^{11}$

\section{Experimental design}

This was a comparative, randomized, placebo-controlled, parallel group study.

\section{Day 1}

- Animals were fasted for 20 hours

- $2 \mathrm{ml}$ blood was collected from marginal vein of the ear for carrying out baseline investigations viz. FBS and serum insulin

- After collection the animals were given a single oral dose of $2 \%$ gum acacia

- Blood samples $(0.5 \mathrm{ml})$ were drawn at 1,2 and 4 hours for estimation of blood glucose and serum insulin (1-1.5 ml) at 2 hours.

After 2 days

- $2 \mathrm{ml}$ blood sample for baseline FBS and serum insulin was collected after 20 hours fasting

- After collection the animals were given a single oral dose of gatifloxacin $25 \mathrm{mg} / \mathrm{kg}$. Blood samples were at 1, 2 and 4 hours for FBS and serum insulin at 2 hours.

\section{Wash out period of 7 days}

- Injection alloxan $140 \mathrm{mg} / \mathrm{kg}$ was given slowly intravenously in the marginal vein of these animals

- On day 3 after alloxan induction, blood samples were taken from the animals (fasting 20 hours), for baseline investigations viz. FBS and serum insulin 
- After collection the animals were given a single oral dose of $2 \%$ gum acacia. Blood samples were drawn at 1, 2 and 4 hours for estimation of FBS and serum insulin at 2 hours.

After 2 days

- $2 \mathrm{ml}$ blood sample for baseline FBS and serum insulin was collected after 20 hours fasting.

After collection the animals were given a single oral dose of gatifloxacin $25 \mathrm{mg} / \mathrm{kg}$. Blood samples were drawn at 1,2 and 4 hours for FBS and serum insulin at 2 hours.

\section{Statistical analysis}

All quantitative data are presented as mean \pm standard deviation (SD). The treatment groups were analysed for baseline comparability by ANOVA. Comparisons of parameters within and between groups for statistical significance at any given time were done by one-way ANOVA. Post-hoc Dunnett's test was applied, to check for significance changes from baseline. For individual comparison of data students ' $t$ ' test (unpaired ' $t$ '- test for between group comparison and paired ' $t$ ' - test for within group comparison) were applied. For all tests a ' $p$ ' value of $<0.05$ was considered as statistically significant.

\section{RESULTS}

\section{Baseline parameters}

The baseline fasting blood glucose (FBS) in $\mathrm{mg} / \mathrm{dl}$ and the serum insulin levels (SI) in $\mu \mathrm{IU} / \mathrm{ml}$ of the New Zealand albino rabbits used for the study, were done. ${ }^{8}$ The mean FBS was $97 \mathrm{mg} / \mathrm{dl}$ with a standard deviation of 1.31.The mean SI was $3.66 \mu \mathrm{IU} / \mathrm{ml}$ with a standard deviation of 0.02 .

\section{Non-diabetic rabbits}

Effect of control and study medications on FBS levels $(m g / d l)$

By applying post-hoc Dunnett's test, the FBS levels at 1, 2 and 4 hours were all found to be significantly more than baseline readings $(\mathrm{p}<0.0001)$. It was found that the FBS levels dropped by $23.17 \mathrm{mg} / \mathrm{dl}$ at 1 hour and $23.96 \mathrm{mg} / \mathrm{dl}$ at 2 hours from baseline. At 4 hours, the FBS levels recovered slightly but still less by $14.89 \mathrm{mg} / \mathrm{dl}$ from baseline. By applying post-hoc Dunnett's test, the FBS values at 1,2 and 4 hours were found to be statistically different from baseline readings ( $\mathrm{p}<0.0001)$ (Table 1).

Table 1: FBS (Mean \pm SD) after control and gatifloxacin in non-diabetic rabbits

\begin{tabular}{|llllll|}
\hline & Baseline & 1 Hour & 2 Hours & 4 Hours & 'p' value \\
\hline Control & $97 \pm 1.31$ & $100.3 \pm 0.29$ & $101.35 \pm 0.29$ & $102.89 \pm 0.22$ & $<0.0001$ \\
\hline Gatifloxacin & $97 . \pm 1.31$ & $73.83 \pm 0.19$ & $73.04 \pm 0.16$ & $82.11 \pm 0.15$ & $<0.0001$ \\
\hline 'p' value" & & $<0.0001$ & $<0.0001$ & $<0.0001$ & \\
\hline " unpaired 't' test applied ; & * Repeat Measures ANOVA applied (p<0.05 taken as significant) &
\end{tabular}

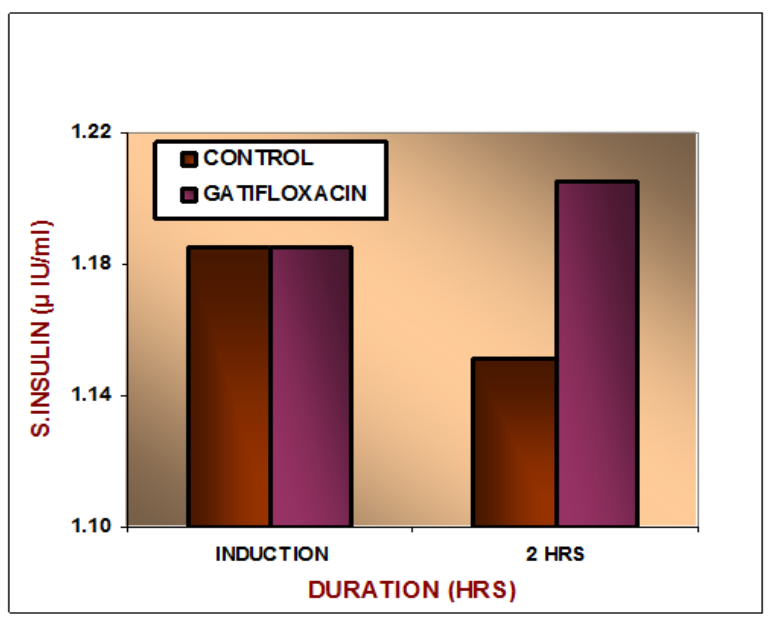

Figure 1: Changes in FBS levels (mg/dl) levels from baseline values in non-diabetic rabbits.
Comparison between FBS levels after control and gatifloxacin ( $\mathrm{mg} / \mathrm{dl})$

At 1 hour and 2 hour interval after gatifloxacin there was a drop by $26.47 \mathrm{mg} / \mathrm{dl}$ and $28.31 \mathrm{mg} / \mathrm{dl}$ in the FBS levels respectively compared to control medication. At 4 hours interval after gatifloxacin, the difference being 20.78 $\mathrm{mg} / \mathrm{dl}$ compared to that after control medication. This reduction in FBS level was found to be statistically significant $(\mathrm{p}<0.0001)$ (Figure 1).

\section{Effect of control and gatifloxacin on S. insulin levels ( $\mu$ $I U / m l)$}

With control, the $\mathrm{S}$. insulin level was $3.62 \mu \mathrm{IU} / \mathrm{ml}$ with a standard deviation of 0.01 , at the end of 2 hours after dosing. It was found that there was a slight decrease in the S. insulin level after the control medication, and this 
decrease was found to be statistically significant ( $\mathrm{p}=$ 0.003 ) compared to baseline reading.

Effect of control and gatifloxacin on S. insulin levels $(\mu$ IU/ml)

With control, the $\mathrm{S}$. insulin level was $3.62 \mu \mathrm{IU} / \mathrm{ml}$ with a standard deviation of 0.01 , at the end of 2 hours after dosing. It was found that there was a slight decrease in the $\mathrm{S}$. insulin level after the control medication, and this decrease was found to be statistically significant $(\mathrm{p}=$ 0.003 ) compared to baseline reading.

With gatifloxacin, the $\mathrm{S}$. insulin level was $4.16 \mu \mathrm{IU} / \mathrm{ml}$ with a standard deviation of 0.01 , at the end of 2 hours after dosing. It was found that the $\mathrm{S}$. insulin level rose by $0.5 \mu \mathrm{IU} / \mathrm{ml}$ at 2 hours from baseline. This rise in $\mathrm{S}$. Insulin level was found to be statistically significant ( $\mathrm{p}<$ 0.0001) (Table 2).

Table 2: $\mathrm{S}$. insulin $($ mean $\pm \mathrm{SD})$ after control and gatifloxacin in non-diabetic rabbits.

\begin{tabular}{|c|c|c|c|}
\hline & Baseline & 2 Hours & 'p' value ${ }^{\#}$ \\
\hline Control & $3.66 \pm 0.02$ & $3.62 \pm 0.01$ & $=0.003$ \\
\hline Gatifloxacin & $3.66 \pm 0.02$ & $4.16 \pm 0.01$ & $<0.0001$ \\
\hline 'p' value & & $<0.0001$ & \\
\hline
\end{tabular}

Comparison between S. insulin levels after control and gatifloxacin

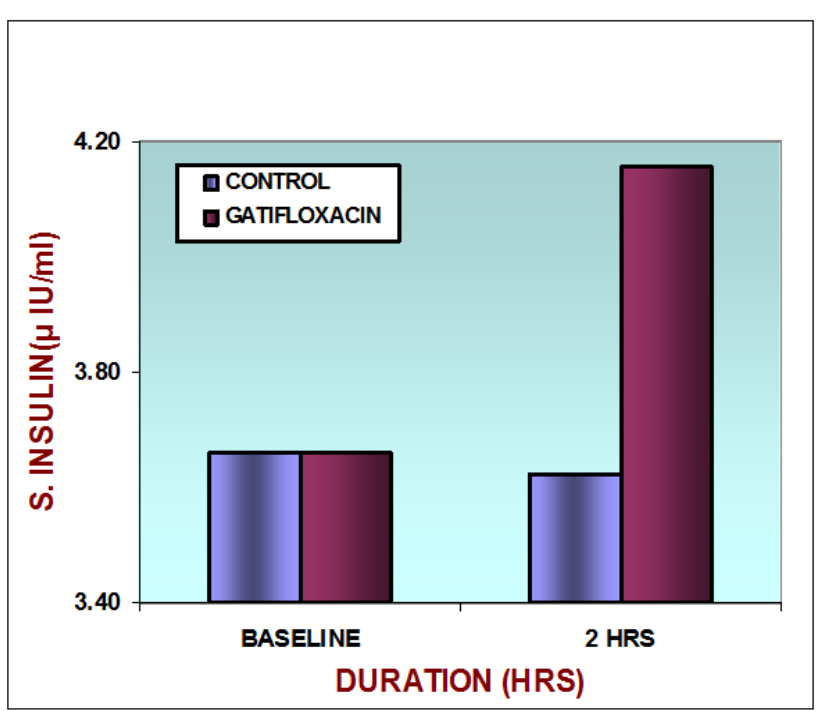

Figure 2: S.I levels $(\mu \mathrm{IU} / \mathrm{ml})$ after control and gatifloxacin in non-diabetic rabbits.

At 2 hours interval after gatifloxacin, there was a rise by $0.54 \mu \mathrm{IU} / \mathrm{ml}$ in the S. insulin level compared to control medication. This rise in S. insulin level was found to be statistically significant $(\mathrm{p}<0.0001)$ (Figure 2).

\section{Diabetic rabbits}

FBS and S. insulin levels after injection alloxan 140 $\mathrm{mg} / \mathrm{kg}$ )

48 hours after injection of alloxan (140 $\mathrm{mg} / \mathrm{kg})$ intravenously and their FBS $(\mathrm{mg} / \mathrm{dl})$ and S. insulin $(\mu$ $\mathrm{IU} / \mathrm{ml}$ ) levels were estimated (Table 3 ).

Table 3: FBS and S. insulin (Mean \pm SD) after alloxan $140 \mathrm{mg} / \mathrm{kg}$.

\begin{tabular}{|lll|}
\hline & Baseline & 48 Hours \\
\hline FBS (mg/dl) & $97.00 \pm 1.31$ & $219.13 \pm 0.83$ \\
\hline S. insulin( $\boldsymbol{\mu} \mathbf{I U} / \mathbf{m l})$ & $3.66 \pm 0.02$ & $1.19 \pm 0.01$ \\
\hline
\end{tabular}

\section{Effect of control and gatifloxacin on FBS levels ( $\mathrm{mg} / \mathrm{dl}$ )}

The mean FBS levels at baseline, 1, 2 and 4 hours after administration of $2 \%$ gum acacia and with $25 \mathrm{mg} / \mathrm{kg}$ oral gatifloxacin as an oral suspension were measured. By applying post-hoc Dunnett's test, the FBS levels at 1, 2 and 4 hours were all found to be significantly more than "induction" values. By applying post-hoc Dunnett's test, these differences in FBS levels at 1and 2 were found to be significantly less than "induction" values ( $p<0.001)$. Also the rise in FBS at 4 hours was significantly higher than the "induction" value (Table 4).

\section{Comparison between FBS levels after control and gatifloxacin}

At 1 hour and 2 hour interval after gatifloxacin, there was a drop by $2.41 \mathrm{mg} / \mathrm{dl}$ and $5.6 \mathrm{mg} / \mathrm{dl}$ in the FBS level compared with control medication. At 4 hours interval after gatifloxacin, there was a slight recovery in the FBS levels compared to 1 and 2 hours, the difference being $7.99 \mathrm{mg} / \mathrm{dl}$ compared to that after control medication. This reduction in FBS level was also found to be statistically significant $(\mathrm{p}<0.0001)$ (Figure 3).

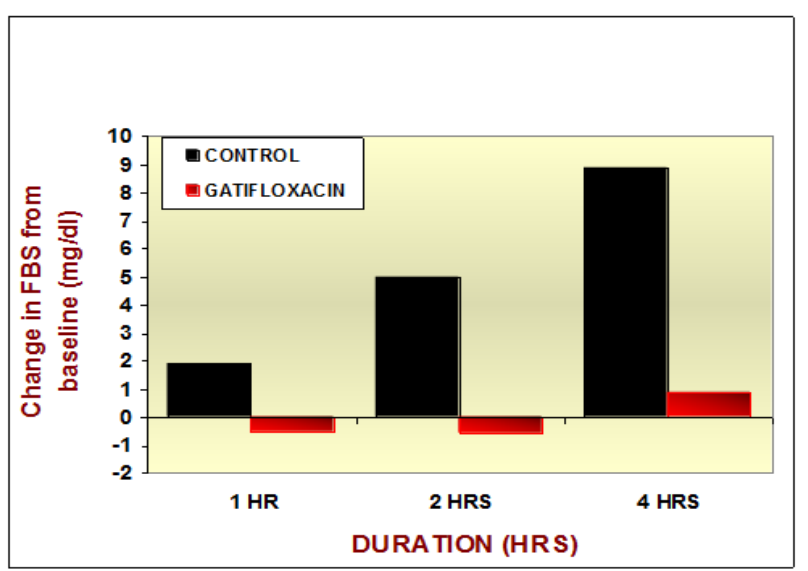

Figure 3: Change in FBS levels (mg/dl) from baseline values in diabetic rabbits. 
Table 4: FBS (mean \pm SD) after control and gatifloxacin in diabetic rabbits.

\begin{tabular}{|llllll|}
\hline & Induction & 1 Hour & 2 Hours & 4 Hours & 'p' value \\
\hline Control & $219.13 \pm 0.83$ & $221.01 \pm 0.10$ & $224.13 \pm 0.30$ & $228 \pm 0.19$ & $<0.0001$ \\
\hline Gatifloxacin & $219.13 \pm 0.83$ & $218.60 \pm 0.29$ & $218.53 \pm 0.16$ & $220.01 \pm 0.49$ & $<0.001$ \\
\hline 'p' value & & $<0.001$ & $<0.0001$ & $<0.0001$ & \\
\# unpaired 't' test applied; $^{*}$ Repeat Measures ANOVA applied (p<0.05 taken as significant). &
\end{tabular}

Effect of control and gatifloxacin on S. insulin levels $(\mu$ $I U / m l)$

The mean S. insulin levels post "induction" and 2 hours after administration of $2 \%$ gum acacia and with $25 \mathrm{mg} / \mathrm{kg}$ oral gatifloxacin as an oral suspension were estimated (Table 5).

Table 5: S. insulin (mean \pm SD) after control and gatifloxacin in diabetic rabbits.

\begin{tabular}{|llll|}
\hline Control & Induction & 2 Hours & 'p' value \\
\hline Gatifloxacin & $1.19 \pm 0.01$ & $1.15 \pm 0.01$ & $=0.0003$ \\
\hline 'p' value & & $1.21 \pm 0.01$ & $=0.0001$ \\
\hline
\end{tabular}

"unpaired ' $\mathrm{t}$ ' test applied; \#paired ' $\mathrm{t}$ ' test applied ( $\mathrm{p}<0.05$ taken as significant).

Comparison between S. insulin levels after control and gatifloxacin

At 2 hours interval after gatifloxacin, there was a rise by $0.06 \mu \mathrm{IU} / \mathrm{ml}$ in the $\mathrm{S}$. insulin level compared to control medication. This rise in S. insulin level was found to be statistically significant $(\mathrm{p}<0.001)$ (Figure 4).

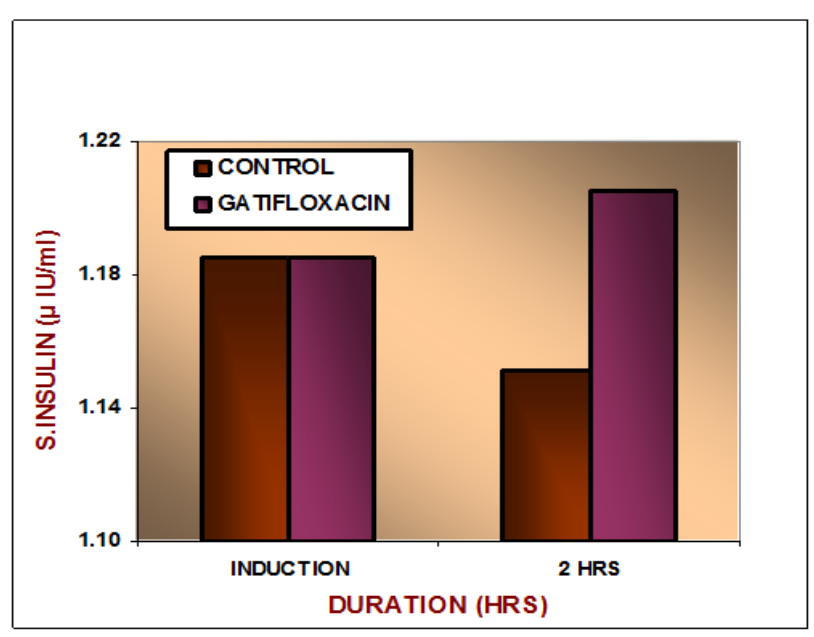

Figure 4: S.I levels $(\mu \mathrm{IU} / \mathrm{ml})$ after control and study medications in diabetic rabbits.

\section{DISCUSSION}

Several clinical studies have reported gatifloxacin to cause both hyper as well as hypoglycemia, especially in elderly age groups, due to reduced renal clearance of the drug. ${ }^{7,15-17}$ Hyperglycemia has been seen to occur more commonly after prolonged intake of the medication. ${ }^{18}$ However, majority of these studies were retrospective, based on case records, and short of establishing any definite relationship between drug intake and blood glucose levels.

In this study, we attempted to evaluate these reporting's by administering oral gatifloxacin to diabetic and nondiabetic rabbits and investigated its effects on fasting blood glucose and serum insulin levels. This was done to clarify the possible mechanisms of gatifloxacin-induced hyperglycemia and hypoglycemia in humans.

By extrapolation from human dose (i.e. $400 \mathrm{mg}$ per day) 2 , the equivalent dose in rabbits was $19 \mathrm{mg} / \mathrm{kg} .{ }^{8}$ Reports state that dysglycemic effect of gatifloxacin is more pronounced if the plasma levels of the drug are increased. ${ }^{7}$ In a clinical situation, this can arise if the creatinine clearance $<40 \mathrm{ml} /$ minute, especially in the elderly age groups. ${ }^{6,7,19,20}$ To simulate this state, we used a slightly higher dose i.e. $25 \mathrm{mg} / \mathrm{kg}$ oral gatifloxacin in the acute single dose study, in both diabetic and non-diabetic rabbits. ${ }^{9}$

\section{Non diabetic rabbits}

The baseline fasting blood sugar (FBS) and serum insulin (S.I.) levels were done for all the 8 animals that were enrolled for this study, and they were found to be comparable.

In the animals fed with control medication i.e. $2 \%$ gum acacia, the FBS levels were seen to rise steadily and significantly $(\mathrm{p}<0.0001)$ at 1,2 and 4 hours after dosing (97 mg/dl at baseline to $102.89 \mathrm{mg} / \mathrm{dl}$ at 4 hours). This was associated with a marginal $(0.04 \mu \mathrm{IU} / \mathrm{ml})$, but significant $(\mathrm{p}=0.003)$, decrease in the $\mathrm{S}$. insulin levels from baseline to 2 hours after dosing.

The probable explanation that can be offered for this observation in both diabetic and non-diabetic rabbits is that the animals might have been under stress thereby increasing their adrenergic response $\left(\alpha_{1}\right.$ mediated hepatic glycogenolysis and gluconeogenesis, $\alpha_{2}$ mediated decreased secretion of insulin and $\beta 2$ mediated muscle glycogenolysis). ${ }^{21}$ This observation can also be attributed to the compensatory mechanisms which come into play during starvation and hypoglycemia to maintain 
euglycemic state i.e. increased glucagon levels, increased glycogenolysis and gluconeogenesis. ${ }^{22}$

In the animals fed with $25 \mathrm{mg} / \mathrm{kg}$ gatifloxacin, the FBS levels recorded at 1,2 and 4 hours, showed a significant $(\mathrm{p}<0.0001)$ decrease in the blood sugar levels, from baseline. The drop in FBS levels was marked during the first 2 hours ( 97 to $73.04 \mathrm{mg} / \mathrm{dl}$ ) and then began to rise at 4 hours $(82.11 \mathrm{mg} / \mathrm{dl})$. This was associated with a significant rise in the $\mathrm{S}$. insulin levels at 2 hours $(\mathrm{p}<0.0001)$.

This drop in FBS levels and rise in S. insulin levels, in the first 2 hours, coincides with the reported peak plasma concentrations of gatifloxacin. ${ }^{5,6,19}$

The gradual rise in FBS levels at 4 hours is probably because the drug had entered its elimination phase.

In vivo, it has been reported that the gatifloxacin concentration in the pancreas, 1 hour after an intravenous injection, was about six-fold that in serum. ${ }^{9}$ Reports also mention that, in patients with type 2 diabetes mellitus, gatifloxacin caused an increase in S. insulin 1 hour after its administration at a conventional dose (i.e. $400 \mathrm{mg}$ once daily), with a downward trend in the FBS level. ${ }^{9}$ In the present study, a significant elevation of the $S$. insulin level was observed at 2 hours after the administration of gatifloxacin at $25 \mathrm{mg} / \mathrm{kg}$.

It has been reported that gatifloxacin induced hyperglycemia is a result of vacuolation of pancreatic $\beta$ cells, which leads to a reduction in insulin levels. ${ }^{18,25}$ This effect of gatifloxacin is evident only on prolonged intake of the drug. ${ }^{18,25}$ However, the exact duration of treatment, to label it as 'prolonged therapy', remains unclear.

\section{Diabetic rabbits}

Diabetes was induced by injecting $140 \mathrm{mg} / \mathrm{kg}$ alloxan into the marginal ear vein of the animals. The FBS levels stabilized 48 hours after injection. The raised FBS and reduced $S$. insulin levels in all the 8 animals were found to be similar.

These values of FBS and S.I. levels henceforth will be referred to as "induction" values.

In the diabetic animals fed with control medication i.e. $2 \%$ gum acacia, the FBS levels were seen to rise steadily $(219.13$ to $228 \mathrm{mg} / \mathrm{dl})$ and significantly $(\mathrm{p}<0.0001)$ at 1,2 and 4 hours after dosing. This was associated with a marginal $(0.04 \mu \mathrm{IU} / \mathrm{ml})$, but significant $(p=0.0003)$, decrease in the $\mathrm{S}$. Insulin levels at 2 hours after dosing.

In the diabetic animals fed with $25 \mathrm{mg} / \mathrm{kg}$ gatifloxacin, the FBS levels were seen to decrease marginally (219.13 to $218.53 \mathrm{mg} / \mathrm{dl}$ ) and significantly at 1 and 2 hours $(p<0.001)$. However at 4 hours, the FBS levels rose slightly $(0.88 \mathrm{mg} / \mathrm{dl})$, but significantly $(\mathrm{p}<0.001)$ from the baseline induction value. This was associated with a small $(0.02 \mu \mathrm{IU} / \mathrm{ml})$ but significant rise in the $\mathrm{S}$. insulin levels at 2 hours $(\mathrm{p}=0.0001)$.

This drop in FBS levels and rise in S. insulin levels, in the first 2 hours, coincides with the reported peak plasma concentrations of gatifloxacin. ${ }^{5,6,19}$

The gradual rise in FBS levels at 4 hours is probably because the drug had already entered its elimination phase and, as a result, its effect was waning off.

When compared to the non-diabetic animals, it was seen that gatifloxacin induced decrease in FBS levels in diabetic ones was less marked, with reference to their respective baselines. The same can be commented about the $\mathrm{S}$. insulin levels, which increased by a smaller fraction in the diabetic animals than in non-diabetic ones, with reference to their respective baselines. This can be explained on the grounds that since the diabetic animals already had a partially destroyed pancreas (alloxan induced) the insulin reserves were lower in these animals. Hence, following gatifloxacin administration, the insulin released was less compared to non-diabetic animals and thereby the drop in FBS level was also lesser than that compared to non-diabetic animals.

The drop in FBS coupled with the rise in S.I. levels after oral gatifloxacin, hints at a probable hypoglycemic effect of the drug, brought about by an increase in insulin secretion from the $\beta$-cells of pancreas. More importantly, this hypoglycemic effect of oral gatifloxacin is not just restricted to diabetic states, but in fact, is more marked in the non-diabetic state.

Some recent PMS and case control studies have reflected upon a possible role of gatifloxacin in the causation of dysglycemic i.e. both hypo as well as hyperglycemia in elderly patients. ${ }^{2,5,15-17}$ However, definitive reports on this adverse effect of gatifloxacin are still lacking. This study was done to evaluate if dysglycemic effects were exerted by gatifloxacin and whether this could have a deleterious effect, especially in diabetic patients, on concurrent oral hypoglycemic agents. It therefore supports earlier reports claiming that Gatifloxacin causes increased release of insulin leading to hypoglycemia. ${ }^{9,23,24}$

\section{CONCLUSION}

Our study showed a hypoglycemic effect of gatifloxacin, on a single dose oral administration, at a dose slightly higher than therapeutic dose i.e. $25 \mathrm{mg} / \mathrm{kg}$, in both diabetic and non-diabetic states. Our study also showed that serum insulin levels were significantly raised after the afford mentioned dose was administered in both diabetic and non-diabetic rabbits used in the study. However, the reduced blood glucose concentrations and raised insulin levels returned to near baseline values by about 4 hours 
after the dose was administered. The fall in blood sugar levels following a single oral dose of gatifloxacin was seen in both diabetic and non-diabetic rabbits.

\section{Funding: No funding sources}

Conflict of interest: None declared

Ethical approval: The study was approved by the Institutional Ethics Committee

\section{REFERENCES}

1. Powers AC. Diabetes mellitus. In, Harrison's Principles Of Internal Medicine, $16^{\text {th }}$ edition, Braunwald E, Fauci AS, 2005;2:2152-62.

2. Emmerson AM. The quinolones: decades of development and use, Journal of Antimicrobial Chemotherapy. 2003;51(S1):13-20.

3. Park-Wyllie LY, Juurlink DN, Kopp A, Shah BR, Stukel TA, Stumpo C, Dresser L, Low DE, Mamdani MM. Outpatient gatifloxacin therapy and dysglycemia in older adults. New England Journal of Medicine. 2006;354(13):1352-61.

4. Onyenwenyi AJ, Winterstein AG, Hatton RC. An evaluation of the effects of gatifloxacin on glucose homeostasis. Pharmacy world and science. 2008;30(5):544-9.

5. Petri WA. Sulfonamides, trimethoprimsulfamethoxazole, quinolones and agents for urinary tract infections. In, Goodman and Gilman's, The Pharmacological Basis of Therapeutics; Laurence L. Brunton, John S. Lazo, Keith L. Parker, $11^{\text {th }}$ edition, pa1; 2011:119-1122.

6. Myers B, Canada S. Health canada-endorsed important safety information on tequin (gatifloxacin). Available at www.hc-sc.gc.ca.

7. Park-Wyllie LY, Juurlink DN, Kopp A, Shah BR, Stukel TA, Stumpo C, et al. Outpatient gatifloxacin therapy and dysglycemia in older patients. N Engl J Med. 2006;354:1352-61.

8. Ghosh MN. Toxicity Studies, In Fundamentals of Experimental Pharmacology, $3^{\text {rd }}$ edition; 2007:192.

9. Ishiwata Y. Effects of gatifloxacin on serum glucose concentration in normal and diabetic rats, biological and pharmaceutical bulletin; 2006;29(3):527-31.

10. Tietz NW. In: Clinical guide to laboratory tests, W. B. Saunders Co. Philadelphia; 1976:238.

11. Nakagawa S, Nakayama H. A simple method for the determination of serum free insulin levels in insulin treated patients. Diabetes. 1973;22:590-600.
12. Gupta SK. Antidiabetic agents. In, Drug Screening Methods, $1^{\text {st }}$ edition; 2004:306-329.

13. Davis SN. Insulin, oral hypoglycemic agents and the pharmacology of the endocrine pancreas. In, Goodman and Gilman's, The Pharmacological Basis of Therapeutics; Laurence L. Brunton, John S. Lazo, Keith L. Parker, $11^{\text {th }}$ edition, 2006; 1634-40.

14. Nolte MS, Karam JH. Pancreatic hormones and antidiabetic drugs. In, Basic and Clinical Pharmacology, $9^{\text {th }}$ edition, Katzung BG. 2004;695711.

15. Kendall C, Wooltorton E. People with diabetes should avoid antibiotic gatifloxacin. Canadian Medical Association Journal. 2006;174(8):1089-90.

16. Zvonar R. Gatifloxacin-induced Dysglycemia. American Journal of Health-System Pharmacy. 2006;63(21):2087-92.

17. Blommel AL. Severe hyperglycemia during renally adjusted gatifloxacin therapy. The Annals of Pharmacotherapy; 2005;1349-135.

18. Happe MR. Gatifloxacin- induced hyperglycemia, annals of internal Medicine. 2004;141(12):698-9.

19. Perry CM. Gatifloxacin, ADIS New Drug Profile, Drugs. 1999;58(4):683-96.

20. Ambrose PG. Gatifloxacin and the elderly: pharmacokinetic-pharmacodynamic rationale for a potential age-related dose reduction. Journal of Antimicrobial Chemotherapy. 2003;52:435-40.

21. Westfall TC. Neurotransmission, drugs acting at synaptic and neuroeffector junctional sites. In, Goodman and Gilman's, The Pharmacological Basis of Therapeutics; Laurence L. Brunton, John S. Lazo, Keith L. Parker, $11^{\text {th }}$ edition; 2007;142-145.

22. Ganong WF. Endocrinology, metabolism and reproductive function, Ganong-Review of Medical Physiology 21st edition; 2010.

23. Maeda N. Increase in insulin release from rat pancreatic islets by quinolone antibiotics. British Journal of Pharmacology. 1996;117(2):372-6.

24. Saraya A. Effects of fluoroquinolones on insulin secretion and $\beta$-cell ATP sensitive $\mathrm{K}+$ channels. European Journal of Pharmacology 2004;497(1)1117.

25. Yamada C. Gatifloxacin acutely stimulates insulin secretion and chronically suppresses insulin biosynthesis. European Journal of Pharmacology. 2006;553(1-3):67-72.

Cite this article as: Khobragade AA, Khopkar MP, Patel SB, Kosale SP, Jalikar K. An acute experimental study to evaluate the effect of gatifloxacin on blood sugar levels in diabetic and non-diabetic rabbits. Int $\mathrm{J}$ Basic Clin Pharmacol 2016;5:1509-15. 